\title{
Indução de brotações in vitro de Dendrobium phalaenopsis Deang Suree em função do tempo de cultivo, luminosidade e BAP(1)
}

\author{
YARA BRITO CHAIM JARDIM ROSA ${ }^{(2)}$; CRYSLAINE CINTIA ALVES DOS REIS(2); JAQUELINE CLARA LONGO \\ CASEMIRO(2); JACKELINE SCHULTZ SOARES ${ }^{(2)}$; JOSÉ CARLOS SORGATO(2) e CAMILA SOARES ROSA LEMES(2)
}

\begin{abstract}
RESUMO
O cultivo in vitro permite a produção de grande quantidade de plantas. Entretanto, alguns aspectos do cultivo de orquídeas ainda são pouco estudados. O presente trabalho analisou condições de luminosidade, tempos de cultivo e concentrações de BAP na brotação in vitro de Dendrobium phalaenopsis Deang Suree. Para tanto, foi realizada a análise quantitativa de parâmetros biométricos de plantas cultivadas por 90 e 180 dias em meio $1 / 2$ MS sob diferentes condições de luminosidade $\left(18,90 \mu \mathrm{mol} \mathrm{m}^{-2} \mathrm{~s}^{-1} ; 14,85 \mu \mathrm{mol} \mathrm{\textrm {m } ^ { - 2 }}\right.$ $\left.\mathrm{s}^{-1} ; 9,45 \mu \mathrm{mol} \mathrm{m}^{-2} \mathrm{~s}^{-1}\right)$ e concentrações de $\operatorname{BAP}\left(0 ; 0,5 ; 1 ; 1,5 ; 2 ; 2,5\right.$ e $\left.3 \mathrm{mg} \mathrm{L}^{-1}\right)$. Os melhores resultados de brotação foram obtidos

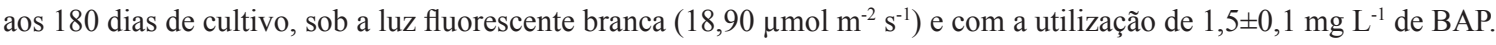

Palavras-chave: Floricultura, citocinina, propagação in vitro.
\end{abstract}

\section{ABSTRACT \\ Cultivation period, lighting conditions and BAP concentrations on in vitro induction shoots of Dendrobium phalaenopsis Deang Suree}

The technique of in vitro micropropagation allows the production of large amounts of plants. However, some aspects of the orchid's in vitro micropropagation are still poorly studied. This study analyzed the lighting conditions, time of cultivation and BAP concentrations on in vitro budburst of Dendrobium phalaenopsis Deang Suree. Therefore, a quantitative analysis of biometric parameters of plants grown during 90 and 180 days on $1 / 2 \mathrm{MS}$ medium under different lighting conditions $\left(18.90 \mathrm{~mol} \mathrm{~m}^{-2} \mathrm{~s}^{-1}, 14.85\right.$ $\left.\mathrm{mol} \mathrm{m} \mathrm{s}^{-1}, 9.45 \mathrm{~mol} \mathrm{~m}^{-2} \mathrm{~s}^{-1}\right)$ and concentrations of $\operatorname{BAP}\left(0 ; 0.5 ; 1 ; 1.5 ; 2 ; 2.5 \mathrm{e} 3 \mathrm{mg} \mathrm{L}^{-1}\right)$. The best results of budburst were obtained during 180 days, under white fluorescent light $\left(18.90 \mathrm{~mol} \mathrm{~m}^{-2} \mathrm{~s}^{-1}\right)$ and using $1.5 \pm 0.1 \mathrm{mg} \mathrm{L}^{-1}$ of BAP.

Keywords: Floriculture, cytokinin, in vitro propagation.

\section{INTRODUÇÃO}

Dentre as orquídeas do gênero Dendrobium, a orquídea Dendrobium phalaenopsis Deang Suree é uma das mais populares plantas de corte do comércio mundial de flores (MEN et al., 2003). A orquídea é nativa da Oceania e apresenta inflorescências com diferentes tonalidades, comprimento e número de flores (BECHTEL et al. 1985; RORIZ, 2000). No Mato Grosso do Sul, floresce entre março e julho, produzindo hastes com 8 a 16 flores de 5 $\mathrm{cm}$ de diâmetro (SORGATO et al., 2015), sendo uma das variedades mais comercializadas no país, conhecida como "orquídea do dia das mães".

A técnica de cultivo in vitro tem sido amplamente utilizada na propagação de orquídeas, porque além de propiciar maiores percentuais de germinação em relação à germinação natural (ARAÚJO et al., 2006), reduz os custos de produção, e contribui para o fornecimento de plantas em larga escala e com alta qualidade fisiológica (STANCATO et al, 2001).

Dentre os fatores que influenciam o sucesso do cultivo in vitro, salienta-se o tempo de cultivo e a composição do meio de cultura. A suplementação dos meios nutritivos com reguladores de crescimento tais como: auxinas, citocininas e giberelinas, podem auxiliar no desenvolvimento das culturas (GRATTAPAGLIA e MACHADO, 1998), além de reduzir o tempo de cultivo. As citocininas influenciam quase todas as fases de desenvolvimento das plantas, promovendo: divisão, alongamento e diferenciação celular, retardando a senescência, propiciando a quebra da dominância apical e induzindo proliferação de gemas axilares (HWANG et al., 2012; MURAI, 2014). Dentre as citocininas mais utilizadas no cultivo in vitro destaca-se a benzilaminopurina (BAP) (SOARES et al., 2012; STEFANELLO, et al., 2009).

Além dos reguladores de crescimento, outro fator que pode influenciar o cultivo in vitro é a condição de luminosidade (BRAGA et al., 2009). Embora com comprovada ação sobre o desenvolvimento vegetal (MORINI e MULEO, 2003), o efeito da luz no cultivo in vitro ainda é pouco estudado e os resultados são pouco conclusivos (BRAGA et al., 2009).

Em vista do exposto, desenvolveu-se este trabalho com o objetivo de identificar as melhores condições de luminosidade, tempos de cultivo e concentrações de BAP na brotação in vitro de Dendrobium phalaenopsis Deang Suree.

\section{MATERIAL E MÉTODOS}

O trabalho foi desenvolvido no Laboratório de Cultivo in vitro da Faculdade de Ciências Agrárias (FCA) da Universidade Federal da Grande Dourados (UFGD), de agosto de 2011 a fevereiro de 2012.

Foram utilizadas plantas de Dendrobium phalaenopsis Deang Suree com 1,5 cm de altura, providas de duas folhas, oriundas de semeadura in vitro e cultivadas por 180 dias,

\footnotetext{
(1) Recebido em 10/02/2014 e aceito em 16/10/2015.

(2) Universidade Federal da Grande Dourados (UFGD), Faculdade de Ciências Agrárias, Dourados-MS, Brasil. * Autor correspondente: ybcjrosa@ gmail.com
} 
em meio MS (MURASHIGE e SKOOG, 1962), e sala de crescimento com temperatura média $25 \pm 2{ }^{\circ} \mathrm{C}$, fotoperíodo de 12 horas e luminosidade de $20,0 \mu \mathrm{mol} \mathrm{m}^{-2} \mathrm{~s}^{-1}$, obtida por meio de duas lâmpadas brancas fluorescentes de $40 \mathrm{~W}$ cada.

Os tratamentos constaram da adição de sete concentrações de $\operatorname{BAP}\left(0 ; 0,5 ; 1 ; 1,5 ; 2 ; 2,5\right.$ e $\left.3 \mathrm{mg} \mathrm{L}^{-1}\right)$ ao meio MS 1/2 (MS na metade da sua concentração de sais), enriquecido com $0,015 \mathrm{mg} \mathrm{L}^{-1}$ de ácido naftalenoacético (ANA). O pH dos meios foi ajustado para 5,8 utilizando hidróxido de potássio P.A $(0,1 \mathrm{M})$. Frascos de vidro com capacidade de $600 \mathrm{~mL}$ providos de tampa metálica receberam $80 \mathrm{~mL}$ de cada meio, posteriormente, foram esterilizados em autoclave à $120^{\circ} \mathrm{C}$ e $1 \mathrm{~atm}$ de pressão por 20 minutos.

Após o resfriamento dos meios de cultivo, em ambiente asséptico, três plantas de D. phalaenopsis foram colocadas em cada frasco, os quais, em seguida, foram tampados e as culturas acondicionadas em sala de crescimento com temperatura média de $25 \pm 2^{\circ} \mathrm{C}$ e fotoperíodo de $12 \mathrm{~h}$, sob três condições de luminosidade: $18,90 \mu \mathrm{mol} \mathrm{m} \mathrm{m}^{-2} \mathrm{~s}^{-1}$ (luz fluorescente branca); 14,85 $\mu \mathrm{mol} \mathrm{m} \mathrm{m}^{-2} \mathrm{~s}^{-1}$ (luz fluorescente branca + luz fluorescente vermelha GRO-LUX ${ }^{\circledR}$ ) e 9,45 $\mu \mathrm{mol} \mathrm{m} \mathrm{m}^{-2} \mathrm{~s}^{-1}$ (luz fluorescente vermelha GRO-LUX ${ }^{\circledR}$ ).

Após 90 dias de cultivo, a metade das culturas foi avaliada quanto ao comprimento de parte aérea e comprimento da maior raiz da planta, número de brotos por planta, número de raízes e de folhas por broto, massa de matéria fresca do broto. $\mathrm{O}$ restante das culturas foram subcultivadas em meios de igual composição e mantidos em sala de crescimento, nas mesmas condições de temperatura, fotoperíodo e intensidade luminosa por mais 90 dias. Ao término deste período as culturas foram avaliadas quanto às mesmas características do período anterior.

$\mathrm{O}$ delineamento experimental utilizado foi $\mathrm{o}$ inteiramente casualizado, e os tratamentos arranjados em esquema de parcelas sub-subdivididas, sendo alocadas nas parcelas as três condições de luminosidade, nas subparcelas as sete concentrações de BAP e nas sub-subparcelas, os dois tempos de cultivo com três repetições constituídas de quatro frascos.

Todas as características foram submetidas à análise de variância e havendo diferenças significativas, as médias relacionadas aos tempos de cultivo foram comparadas pelo teste $\mathrm{t}$ de Student, as médias relacionadas às condições de luminosidade e foi realizado o teste de Tukey, ambas até $5 \%$ de significância, e aquelas médias relacionadas às concentrações de BAP, por análise de regressão com a utilização do programa SISVAR 5.3 (FERREIRA, 2011).

\section{RESULTADOS}

Houve interação entre os três fatores estudados $(p<0,01)$ sobre todas as variáveis estudadas. $\mathrm{O}$ número de brotos por planta (NBP) foi maior aos 180 que aos 90 dias de cultivo, em todas as luminosidades estudadas (Figuras 1A, 1B, 1C).

Aos 90 dias de cultivo, apenas as plantas cultivadas sob luz branca (B) foram influenciadas pelas concentrações de BAP. O maior NBP (26), nessa condição luminosa foi obtido com a concentração calculada de $1,7 \mathrm{mg} \mathrm{L}^{-1}$ BAP (Figura 1A). Nas demais condições de luminosidade, independentemente das concentrações de BAP, o NBP foi de 7,7 para luz vermelha (V) e de 9,2 para a luz vermelha + branca (VB).

Aos 180 dias, o NBP foi afetado tanto pelas condições de luminosidade quanto pelas concentrações de BAP utilizadas. Os maiores NBP em todas as luminosidades

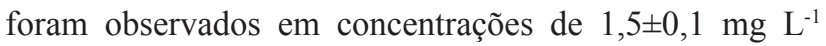
BAP. A luz B proporcionou 41 brotos, enquanto que a luz $\mathrm{V}$ e a VB proporcionaram 24 e 25 brotos, respectivamente (Figuras 1A, 1B, 1C).

Brotos cultivados por 180 dias apresentaram, de maneira geral, maior massa de matéria fresca (MFB) que aqueles cultivados por 90 dias. Tanto aos 90 quanto aos 180 dias, a maior MFB foi obtida na ausência de BAP e sob luz B ou VB. Sob luz V apenas o tempo de cultivo influenciou a massa de matéria fresca dos brotos que foi de 0,12 e 0,19 g aos 90 e 180 dias, respectivamente (Figuras 1D, 1E, 1F).

A menor MFB de plantas cultivadas por 90 ou 180 dias foi obtida sob luminosidade B ou VB. Aos 90 dias os brotos apresentaram massa de matéria fresca de 0,07 g (luz B) e $0,02 \mathrm{~g}$ (luz VB) com a concentração calculada de $2,1 \mathrm{mg} \mathrm{L}^{-1}$ BAP. Aos 180 dias os brotos cultivados com concentração calculada de 1,6 $\mathrm{mg} \mathrm{L}^{-1}$ BAP sob luz B ou VB apresentaram em média 0,13 g (Figuras 1D, 1F).

À medida que o tempo de cultivo aumentou houve o aumento no número de folhas por broto (NFB). Sob luz B não houve efeito da utilização de BAP, sendo que aos 90 dias os brotos apresentaram 3,6 folhas e, aos 180 dias, 4,9 folhas (Figura 2A).

Sob luz V, a utilização de BAP influenciou o NFB apenas nas plantas cultivadas por 90 dias. Para esse tempo de cultivo, o maior NFB (8) foi observado com a utilização de $3 \mathrm{mg} \mathrm{L}^{-1}$ BAP e o menor $(3,3)$ com concentração calculada de $1,2 \mathrm{mg} \mathrm{L}^{-1}$. Aos 180 dias de cultivo, as plantas apresentaram 5,9 folhas, independentemente das concentrações de BAP estudadas (Figura 2B).

Sob luz VB, plantas cultivadas por 90 dias, apresentaram 3,3 folhas, enquanto que aquelas cultivadas por 180 dias apresentaram 7,1 folhas na presença de $3 \mathrm{mg} \mathrm{L}^{-1}$ e 4,4 folhas na presença da concentração calculada de $1,3 \mathrm{mg} \mathrm{L}^{-1}$ BAP (Figura 2C).

O tempo de cultivo de 180 dias, a presença da luz vermelha combinada com $3 \mathrm{mg} \mathrm{L}^{-1}$ de BAP foi a condição que promoveu maior NFB.

De maneira geral, o aumento das doses de BAP diminuiu o número de raízes por broto (NRB). Plantas cultivadas por 90 dias sob as luzes $\mathrm{B}$ ou $\mathrm{VB}$ apresentaram maior $\operatorname{NRB}(5,8)$ quando cultivadas na ausência do regulador de crescimento. Nesse mesmo tempo de cultivo, as plantas cultivadas sob luz $\mathrm{V}$ apresentaram 0,28 raízes por broto, independentemente da concentração de BAP utilizada (Figura 2 D, E, F). 

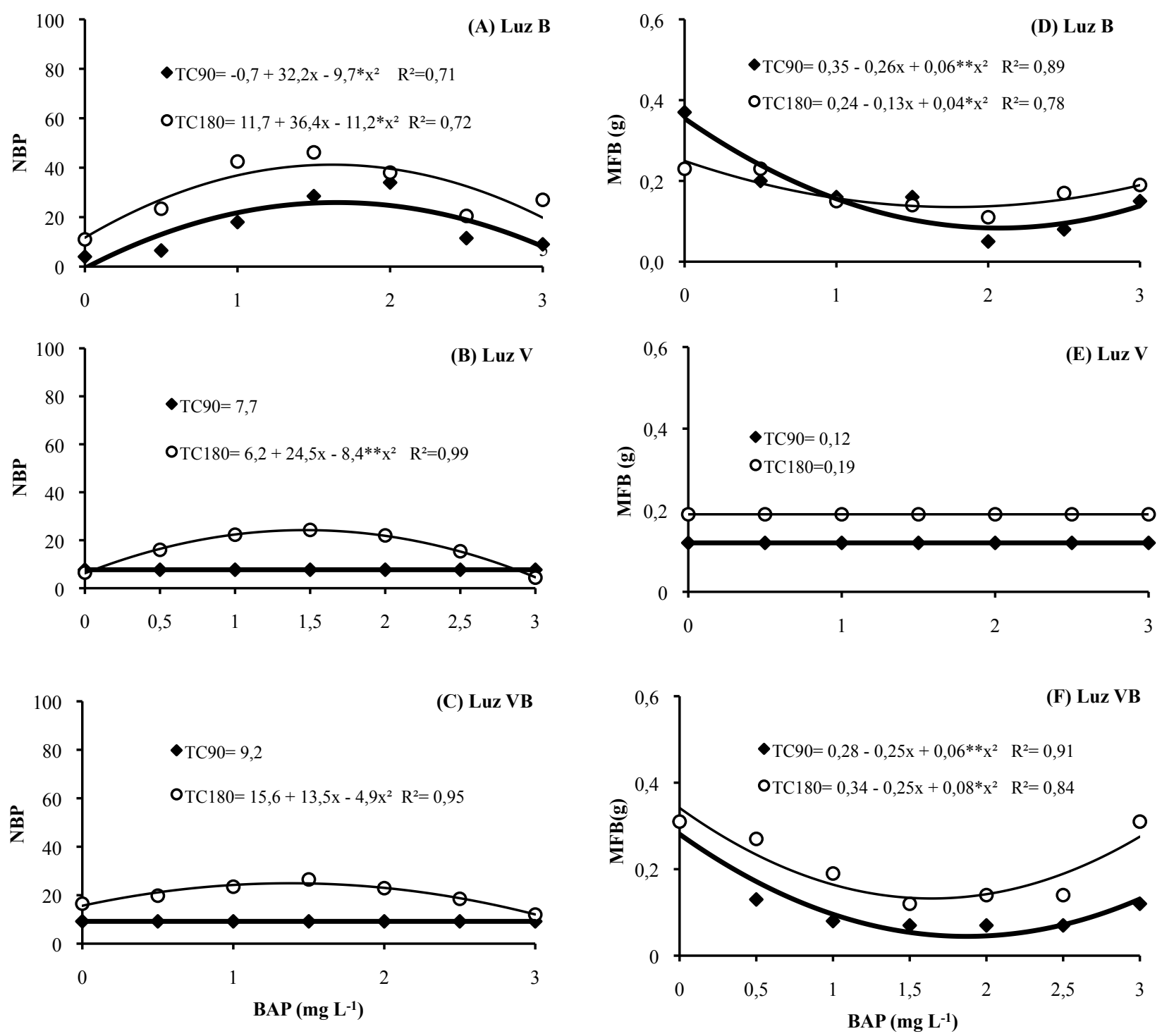

Figura 1. Número de brotos por planta (NBP) e massa de matéria fresca de brotos (MFB) de Dendrobium phalaenopsis Deang Suree cultivadas na presença de BAP e sob diferentes condições de luminosidade. Luz B: $18,90 \mu \mathrm{mol} \mathrm{m} \mathrm{m}^{-2} \mathrm{~s}^{-1}$ (luz fluorescente branca); Luz V: 9,45 $\mu \mathrm{mol} \mathrm{m}^{-2} \mathrm{~s}^{-1}$ (luz fluorescente vermelha GROLUX $^{\circledR}$ ) e Luz VB: $14,85 \mu \mathrm{mol} \mathrm{m} \mathrm{m}^{-2} \mathrm{~s}^{-1}$ (luz fluorescente branca + luz fluorescente vermelha GRO-LUX ${ }^{\circledR}$ ).

Figure 1. Number of buds per plant (NBP) and fresh weight of buds (MFB) of Dendrobium phalaenopsis Deang Suree cultured in BAP presence and under different lighting conditions. Luz B: $18.90 \mu \mathrm{mol} \mathrm{m}^{-2} \mathrm{~s}^{-1}$ (white fluorescent light); Luz $\boldsymbol{V}: 9.45 \mu \mathrm{mol} \mathrm{m} \mathrm{m}^{-2} \mathrm{~s}^{-1}$ (red fluorescent light GRO-LUX ${ }^{\circledR}$ ) and $\mathbf{L u z} \mathbf{V B}: 14.85$ $\mu \mathrm{mol} \mathrm{m} \mathrm{m}^{-2} \mathrm{~s}^{-1}$ white fluorescent light + red fluorescent light GRO-LUX $X^{\circledR}$ ).

Aos 180 dias, o maior NRB foi observado em concentrações calculadas de BAP variando de 0 a $0,3 \mathrm{mg}$ $\mathrm{L}^{-1}$. Brotos com 4,0 raízes foram produzidos sob luz B, com 3,9 sob VB e com 2,5 na V.

O tempo de cultivo de 180 dias promoveu aumento no comprimento da parte aérea da planta (CPAP). Nesse período, plantas cultivadas sob luz $\mathrm{V}$ ou VB apresentaram maiores CPAP na ausência de BAP 37,4 e $56,0 \mathrm{~mm}$ respectivamente. Entretanto aquelas cultivadas sob luz B apresentaram maior CPAP $(33,2 \mathrm{~mm})$ na presença de 3 $\mathrm{mg} \mathrm{L}^{-1}$ de BAP indicando a combinação específica entre o regulador e a luminosidade utilizada no cultivo (Figuras 3A, 3B, 3C).

Plantas cultivadas por 90 dias sob luz B e VB apresentaram maior CPAP na ausência de BAP (26,8 e 37,1 $\mathrm{mm}$, respectivamente) e aquelas cultivadas sob luz $\mathrm{V}$ não responderam ao regulador de crescimento, apresentando CPAP de 18,2 mm (Figuras 3A, 3B, 3C). 

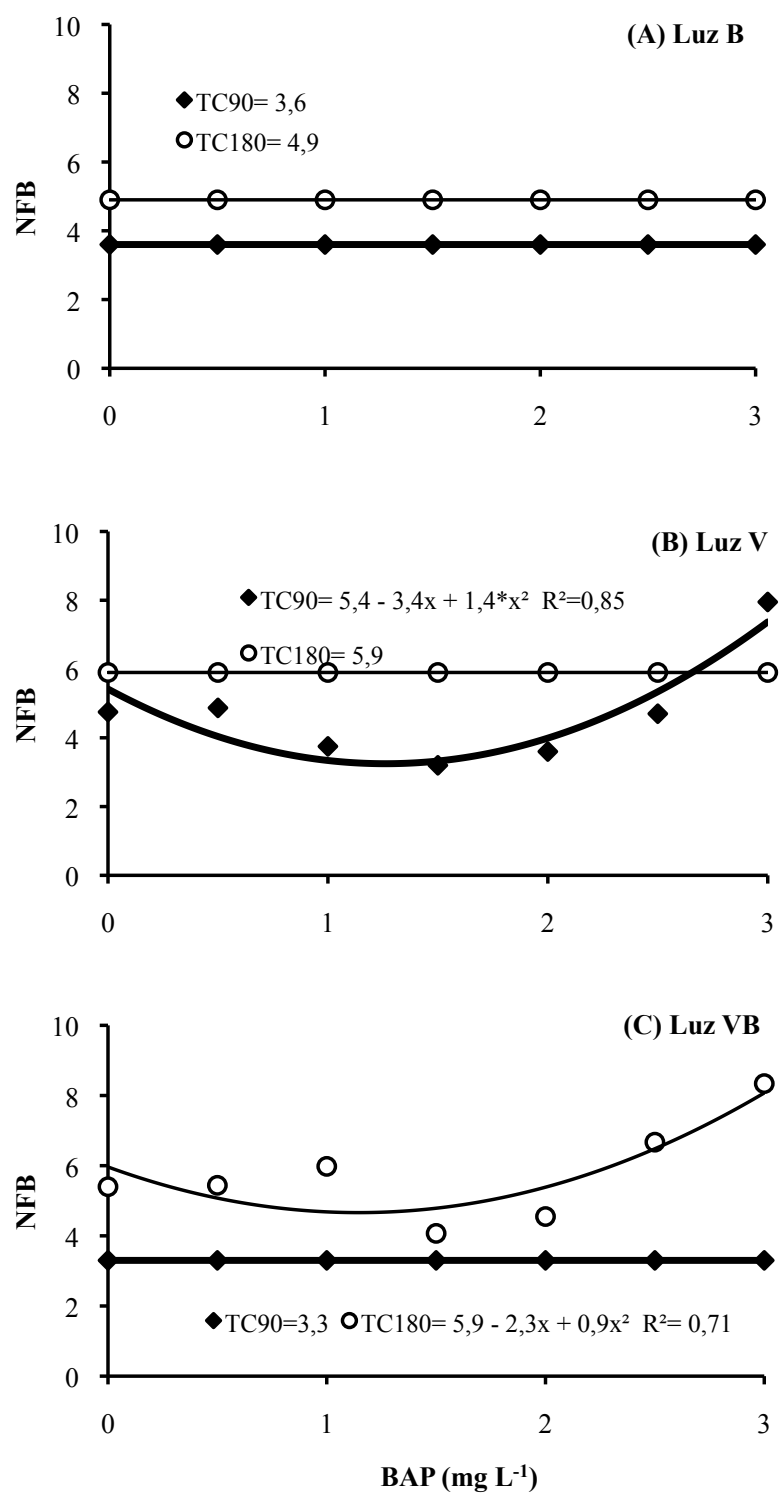
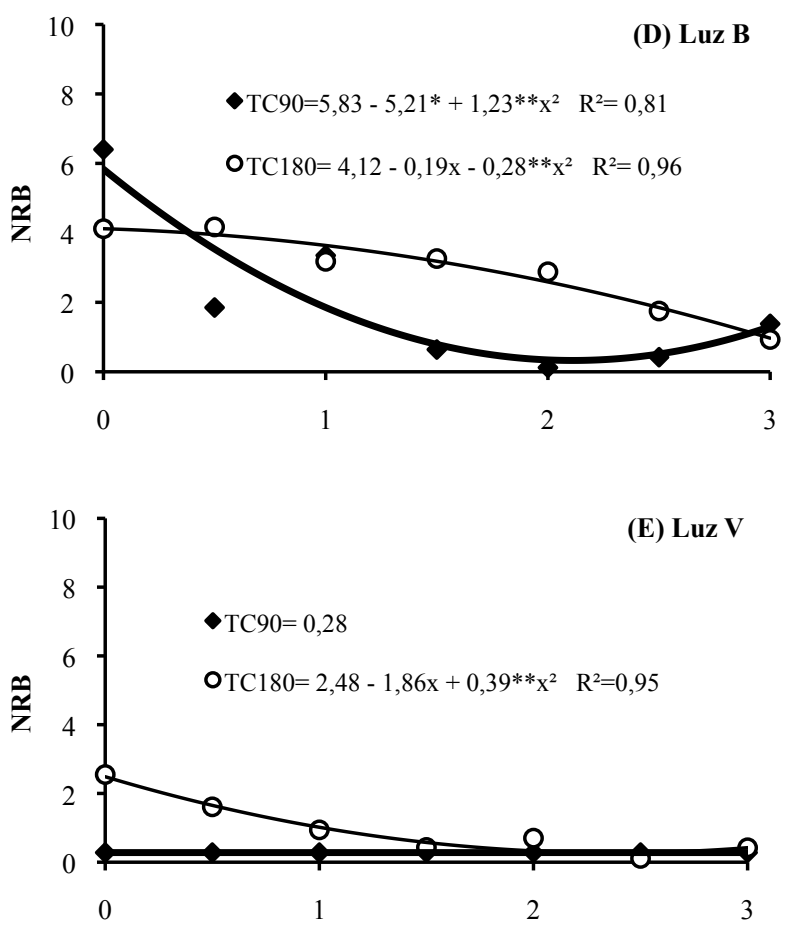

(F) Luz VB

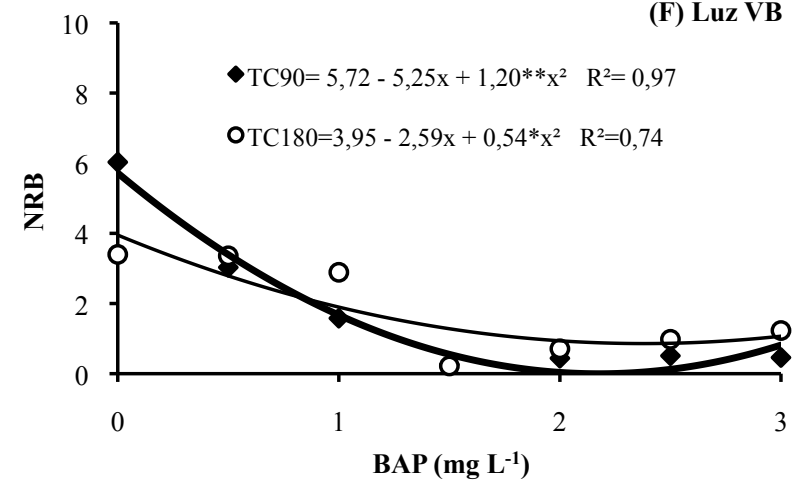

Figura 2. Número de folhas (NFB) e raízes (NRB) por broto de Dendrobium phalaenopsis Deang Suree cultivadas na presença de BAP e sob diferentes condições de luminosidade. Luz B: $18,90 \mu \mathrm{mol} \mathrm{m}^{-2} \mathrm{~s}^{-1}$ (luz fluorescente branca); Luz V: 9,45 $\mu \mathrm{mol} \mathrm{m}^{-2} \mathrm{~s}^{-1}$ (luz fluorescente vermelha GRO-LUX ${ }^{\circledR}$ ) e Luz VB: 14,85 $\mu \mathrm{mol} \mathrm{m} \mathrm{m}^{-2} \mathrm{~s}^{-1}$ luz fluorescente branca + luz fluorescente vermelha GRO-LUX ${ }^{\circledR}$ ).

Figure 2. Number of leaves (NFB) and roots (NRB) per buds of Dendrobium phalaenopsis Deang Suree cultured in BAP presence and under different lighting conditions. Luz B: $18.90 \mu \mathrm{mol} \mathrm{m} \mathrm{m}^{-2} \mathrm{~s}^{-1}$ (white fluorescent light); $\mathbf{L u z} \boldsymbol{V}: 9.45 \mu \mathrm{mol} \mathrm{m}^{-2} \mathrm{~s}^{-1}$ (red fluorescent light GRO-LUX ${ }^{\circledR}$ ) and $\mathbf{L u z} \boldsymbol{V B}$ : $14.85 \mu \mathrm{mol} \mathrm{m} \mathrm{m}^{-2}$ $s^{-1}$ (white fluorescent light + red fluorescent light GRO-LUX $\left.{ }^{\circledR}\right)$.

A presença de BAP no meio de cultivo prejudicou o crescimento da maior raiz da planta (CMRP) nos dois períodos de cultivo e nas três condições de luminosidade. Os maiores valores de CMRP foram observados aos 180 dias de cultivo e na ausência de BAP para todas as condições de luminosidade. A presença de luz B nessa condição de cultivo propiciou maior CMRP. A utilização isolada da luz B produziu raízes com $45 \mathrm{~mm}$ de comprimento. Em contrapartida a presença de luminosidade $\mathrm{V}$, mesmo em combinação com a B, propiciou redução de média de $40 \%$ no CMRP, produzindo plantas com raízes de $24,7 \mathrm{~mm}(\mathrm{~V})$ e 29,3 mm (VB) (Figuras 3D, 3E, 3F).

\section{DISCUSSÃO}

Amultiplicação assexuada de orquídeas está diretamente relacionada à sua capacidade de formação de novos brotos. Os resultados observados neste trabalho permitem inferir 

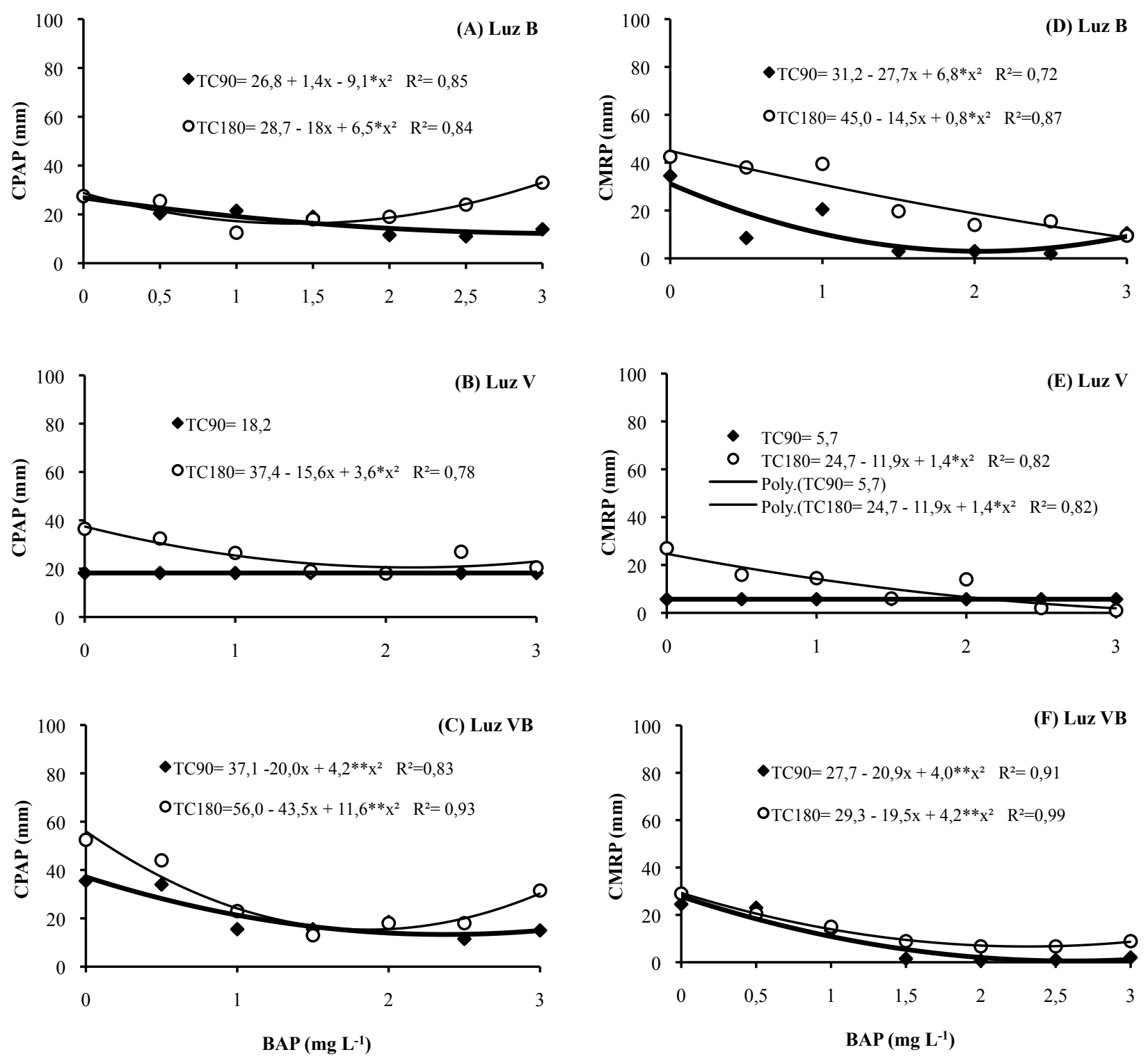

Figura 3. Comprimento da parte aérea (CPAP) e da maior raiz (CMRP) das plantas de Dendrobium phalaenopsis Deang Suree cultivadas na presença de BAP e sob diferentes condições de luminosidade. Luz B: $18,90 \mu \mathrm{mol} \mathrm{m} \mathrm{m}^{-2} \mathrm{~s}^{-1}$ (luz fluorescente branca); Luz V: 9,45 $\mu \mathrm{mol} \mathrm{m} \mathrm{m}^{-2} \mathrm{~s}^{-1}$ (luz fluorescente vermelha GROLUX $^{\circledR}$ ) e Luz VB: $14,85 \mu \mathrm{mol} \mathrm{m} \mathrm{m}^{-2} \mathrm{~s}^{-1}$ (luz fluorescente branca + luz fluorescente vermelha GRO-LUX ${ }^{\circledR}$ ).

Figure 3. Shoot length (CPAP) and largest root (CMRP) of plants of Dendrobium phalaenopsis Deang Suree cultured in BAP presence and under different lighting conditions. Luz B: $18.90 \mu \mathrm{mol} \mathrm{m} \mathrm{m}^{-2} \mathrm{~s}^{-1}$ (white fluorescent light); $\mathbf{L u z} \boldsymbol{V}: 9.45 \mu \mathrm{mol} \mathrm{m} \mathrm{m}^{-2} \mathrm{~s}^{-1}$ (red fluorescent light GRO-LUX $X^{\circledR}$ ) and $\mathbf{L u z} \boldsymbol{V B}: 14.85 \mu \mathrm{mol} \mathrm{m}^{-2} \mathrm{~s}^{-1}$ (white fluorescent light + red fluorescent light $\left.G R O-L U X^{\circledR}\right)$.

que a indução de brotação de $D$. phalaenopsis ocorre com mais intensidade quando cultivadas por 180 dias, na presença de luz branca e de $1,5 \pm 0,1 \mathrm{mg} \mathrm{L}^{-1}$ de BAP.

Resultados semelhantes em relação à utilização de BAP no cultivo do gênero Dendrobium foram descritos por Talukder et al. (2003), que obtiveram maior número de brotações de Dendrobium $s p$. cultivada em meio MS suplementado com 2,5 mg L-1 de BAP; e por Asghar et al. (2011), que relataram maior brotação de Dendrobium nobile em meio O753, suplementado com $2 \mathrm{mg} \mathrm{L}^{-1} \mathrm{de}$
BAP. Ambos os autores constataram que concentrações superiores induziram a redução do número de brotos nas espécies estudadas.

Em sua revisão, Monfort et al. (2012) salientam que as citocininas, quando utilizadas em cultivo in vitro, até determinada concentração estimulam a brotação, entretanto, concentrações acima da ótima propiciam efeitos desfavoráveis à indução de brotos. Segundo os autores isso ocorre em virtude do desequilíbrio hormonal entre os reguladores vegetais presentes no meio de cultivo. 
Sabe-se que a presença de BAP no meio de cultivo, na concentração adequada, desencadeia nas plantas a ativação de um complexo enzimático, o qual possibilita o crescimento vegetativo. Embora a dominância apical possa ser determinada inicialmente pela auxina, os estudos de fisiologia indicam que a citocinina atua no crescimento inicial das gemas laterais, através da promoção da divisão celular (MURAI, 2014).

As concentrações de BAP que propiciaram os menores MFB foram muito próximas àquelas que produziram o maior número de brotações em plantas cultivadas por 180 dias. Nesse tempo de cultivo, a luz B propiciou 41 brotos e a luz VB 25, mas ambas produziram brotos com a mesma massa de matéria fresca $(0,13 \mathrm{~g})$, evidenciando a superioridade da luz B em promover brotações.

Sob luz $\mathrm{V}$ as plantas produziram 24 brotos, porém cada broto apresentou massa de matéria fresca em torno de $0,19 \mathrm{~g}$, com acréscimo de $0,06 \mathrm{~g}$ em relação às demais luminosidades, indicando a superioridade da luz $\mathrm{V}$ em promover ganho de massa de matéria fresca. Esses resultados se contrapõem aos de Galdiano Junior et al. (2012) que verificaram que a massa de matéria fresca das plantas de $C$. loddigesii cultivada em meio $1 / 2$ MS foi favorecida pela luz branca e prejudicada pela luz vermelha.

Desta forma se o objetivo for induzir brotação em $D$. phalaenopsis, para futuros trabalhos de multiplicação assexuada, a utilização de luz B é indicada, entretanto, se o objetivo for produção de plantas de maior, porte indica-se a utilização de luz V.

O crescimento do sistema radicular de $D$. phalaenopsis está associado ao tempo de cultivo e exposição à luminosidade branca, sendo pouco influenciado pelo BAP, uma vez que, o maior número de raízes por broto e o maior comprimento de raiz da planta foram obtidos na ausência do regulador de crescimento.

Os resultados encontrados neste trabalho ratificam os relatos da revisão de Navroski et al. (2014) na qual os autores salientam que concentrações elevadas de citocinina podem inibir ou atrasar a formação de raízes e, além de prejudicar o seu comprimento, podem anular os efeitos benéficos das auxinas sobre a indução do sistema radicular.

As citocininas têm sido relacionadas com diversos aspectos do desenvolvimento das plantas, incluindo a divisão celular, crescimento do caule e raízes, senescência foliar, movimento de nutrientes, desenvolvimento de cloroplastos, fotomorfogênese, entre outros processos (CORTLEVEN e SCHMÜLLING, 2015; HWANG et al., 2012). Embora sejam basicamente biossintetizadas na raiz, não é neste órgão que as citocininas atuam de forma decisiva (MERCIER, 2004).

Segundo Staden et al. (2008), altas concentrações de citocinina $\left(0,5-10 \mathrm{mg} \mathrm{L}^{-1}\right)$ geralmente inibem ou retardam a formação de raízes, além de evitar o seu crescimento. Ainda de acordo com estes autores, as citocininas geralmente não compõem meios onde serão cultivadas plantas que devem ser enraizadas para posterior aclimatização.

De acordo com Mercier (2004), parte do efeito inibitório provocado pelas altas concentrações de citocininas sobre o alongamento radicular pode ser provocado pela indução da produção de etileno endógeno, sugerindo que, neste caso, essas duas classes hormonais atuem de modo sinergético ou aditivo.

O comportamento do sistema radicular de $D$. phalaenopsis apresentado neste trabalho, confirma a influência negativa do aumento da concentração de citocinina sobre o desenvolvimento das raízes.

Quanto à luminosidade, George e Davies (2008), relatam os efeitos benéficos da luz $\mathrm{V}$ no enraizamento em muitas espécies. Entretanto os resultados obtidos neste trabalho se contrapõem aos destes autores, concordando com os apresentados por Galdiano Júnior et al. (2012), que verificaram que o crescimento radicular de Cattleya loddigesii, cultivadas em meio $1 / 2 \mathrm{MS}$, foi prejudicado pela luz vermelha e favorecido pela luz branca; e por Araújo et al. (2009) que observaram maior crescimento de raízes de C. loddigesii, cultivadas em meio WPM, sob luz branca.

De maneira geral, todas as características vegetais de $D$. phalaenopsis apresentaram maiores resultados quando as plantas foram cultivadas sob luz branca, associada ou não com a luz vermelha. Vale ressaltar também que, em ambos os períodos de cultivo, as menores médias para a maioria das características analisadas foram obtidas quando as plantas foram cultivadas sob a luz vermelha, sendo a luz VB condição intermediária entre as outras duas luminosidades.

\section{CONCLUSÃO}

A brotação de Dendrobium phalaenopsis Deang Suree foi favorecida pelo cultivo por 180 dias sob a luz fluorescente branca, em meio $1 / 2$ MS suplementado com $1,5 \pm 0,1 \mathrm{mg} \mathrm{L}^{-1}$ de BAP.

\section{REFERÊNCIAS}

ARAÚJO, A.G.; PASQUAL, M.; PEREIRA, A.; ROCHA, H. Crescimento in vitro de Laelia tenebrosa (Orquidaceae) em diferentes concentrações de sais de Knudson C e carvão ativado. Plant Cell Culture \& Micropropagation, Lavras, v.2, n.2, p.53-106, 2006.

ARAÚJO, A.G.; PASQUAL, M.; RODRIGUES, F.A.; RODRIGUES, J.D.; CASTRO, E.M.; SANTOS, A.M. Crescimento in vitro de Cattleya loddigesii Lindl. em diferentes espectros luminosos associados com ácido giberélico. Ceres, Viçosa, v.56, n.5, p.542-546, 2009.

ASGHAR, S.; AHMAD, T.; HAFIZ, I.A.; YASEEN, M. In vitro propagation of orchid (Dendrobium nobile) var. Emma white. African Journal of Biotechnology, Nairobi, v.10, n.16, p.3097-3103, 2011.

BECHTEL, H.; CRIBB, P.; LAUNERT, E. Orchideen atlas: die Kulturorchideen. Stuttgart: Ulmer, 1985, 475p.

BRAGA, F.T.; PASQUAL, M.; CASTRO, E.D.; DIGNART, S.L.; BIAGIOTTI, G.; PORTO, J.M.P. Qualidade de luz no cultivo in vitro de Dendranthema grandiflorum cv. Rage: características morfofisiológicas. Ciência e Agrotecnologia, Lavras, v.33, n.2, p.502-508, 2009. 
CORTLEVEN, A.; SCHMÜLLING, T. Regulation of chloroplast development and function by cytokinin. Journal of Experimental Botany, Oxford, p. pls015, Publicado online em 4 de abril de 2015. doi:10.1093/jxb/erv132

FERREIRA, D.F. 2011 Sisvar: a computer statistical analysis system. Ciência e Agrotecnologia, Lavras, v.35, n.6, p.1039-1042, 2011.

GALDIANO JUNIOR, R.F.; MANTOVANI, C.; PIVETTA, K.F.L.; LEMOS, E.G.M. Crescimento in vitro e aclimatização de Cattleya loddigesii Lindley (Orchidaceae) com carvão ativado sob dois espectros luminosos. Ciência Rural, Santa Maria, v.42, n.5, p.801-807, 2012.

GEORGE, E.F.; DAVIES, W. Effects of the physical environment. GEORGE, E.F.; HALL, M.A.; KLERK, G.J. Plant propagation by tissue culture. Dordrecht: Springer. 3 ed., 2008. p.423-464.

GRATTAPAGLIA, D.; MACHADO, M.A. Micropropagação. TORRES, A.C.; CALDAS, L.S.; BUSO, J.A. Cultura de tecidos e transformação genética de plantas. Brasília: EMBRAPA-SPI/ EMBRAPA-CNPH, v.1, 1998. p.183-260.

HWANG, I.; SHEEN, J.; MÜLLER, B. Cytokinin signaling networks. Annual Review of Plant Biology, Palo Alto, v.63, n.1 p.353-380, 2012.

MEN, S.; MING, X.; WANG, Y.; LIU, R.; WEI, C.; LI, Y. Genetic transformation of two species of orchid by biolistic bombardment. Plant Cell Reports, Berlin, v.21, n.6 p.592598, 2003.

MERCIER, H. Auxinas. KERBAUY, G.B. Fisiologia Vegetal. São Paulo: Editora Guanabara Koogan S. A., 2004. p.217-249,

MONFORT, L.E.F.; PINTO, J.E.B.P.; BERTOLUCCI, S.K.V.; ROSSI, Z.T.T.; SANTOS, F.M. Efeito do BAP no cultivo in vitro de Ocimum selloi Benth. Revista Brasileira de Plantas Medicinais, Botucatu, v.14, n.3, p.458-63, 2012.

MORINI, S.; MULEO, R. Effects of light quality on micropropagation of woody species. JAIN, S.M.; ISHII, K. Micropropagation of woody trees and fruits. Dordrecht: Kluwer Academic Publishers, 2003. p.3-35.
MURAI, N. Review: Plant growth hormone cytokinins control the crop seed yield. American Journal of Plant Sciences, Irvine, v.5, n.14, p. 2178-2187, 2014.

MURASHIGE, T.; SKOOG, F. A revised medium for a rapid growth and biossays with tabacco tissue cultures. Physiologia Plantarum, Lund, v.15, n.3, p.473-497, 1962.

NAVROSKI, M.C.I.; WALDOW, D.A.G.; REINIGER, L.R.S.; GOLLE, D.P.; CURTI, A.R.; PEREIRA, M.O. Multiplicação in vitro de segmentos apicais caulinares de segurelha (Satureja hortensis L.). Revista Brasileira de Plantas Medicinais, Campinas, v.16, n.1, p. 117-121, 2014.

SOARES, J.S.; ROSA, Y.B.C.J.; SUZUKI, R.M.; SCALON, S.P.Q.; ROSA JUNIOR, E.J. Germinação assimbiótica e desenvolvimento de Dendrobium nobile Lindl. sob efeito de reguladores vegetais no tratamento prégerminativo. Revista Brasileira de Plantas Medicinais, Botucatu, v.14, n.4, p.617-623, 2012.

SORGATO, J.C.; ROSA, Y.B.C.J.; SOARES, J.S.; LEMES, C.S.R.; SOUSA, G.G.D. 2015. Light in intermediate acclimatization of in vitro germinated seedlings of Dendrobium phalaenopsis Deang Suree. Ciência Rural, Santa Maria, v.45, n.2 p.231-237, 2015.

STADEN, J.V.; ZAZIMOLAVA, E.; GEORGE, E.F. Plant regulators II: Cytokinins, their Analogues and Antagonists. GEORGE, E.F.; HALL, M.A.; KLERK, G.J. Plant propagation by tissue culture. Dordrecht: Springer. 2008. p. 205-226.

STANCATO, G.C.; BEMELMANS, P.F.; VEGRO, C.L.R. Produção de mudas de orquídeas a partir de sementes in vitro e sua viabilidade econômica: estudo de caso. Revista Brasileira de Horticultura Ornamental, Campinas, v.7, n.1, p.25-33, 2001.

STEFANELLO, S.; KARSTENM J.; MULLER, T.S.; TOMEZAK, A.P.; BONETT, L.P.; SCHUELTER, A.R. Conversão in vitro de raízes e folhas de Miltonia flavescens Lindl. em protocormos e regeneração de plantas. Ciência e Agrotecnologia, Lavras, v.33, n.1, p.53-59, 2009.

TALUKDER, S.K.; NASIRUDDIN, K.M.; YASMIN, S.; HASSAN, L.; BEGUM, R. Shoot proliferation of Dendrobium Orchid with BAP and NAA. Journal of Biological Sciences, Gaziantep, v.3, n.11, p.1058-1062, 2003. 
